\title{
Foreword: sustainability in agrifood chains and networks
}

\author{
Arnout R.H. Fischer ${ }^{1}$, P.J. Beers ${ }^{2}$, J.C.M. van Trijp ${ }^{1}$, Evert Jacobsen ${ }^{3}$, Hans Mommaas $^{4}$ and A. Veldkamp ${ }^{5}$ \\ ${ }^{1}$ Wageningen University, Marketing and Consumer behaviour group, P.O. Box 8130, 6700 EW Wageningen, the Netherlands; arnout. \\ fischer@wur.nl \\ ${ }^{2}$ Wageningen University, Education and Competence studies group, P.O. Box 8130, 6700 EW Wageningen, the Netherlands \\ ${ }^{3}$ Wageningen University, Plant Sciences group, P.O. Box 386, 6700 AJ Wageningen, the Netherlands \\ ${ }^{4}$ Tilburg University, Department of Leisure Studies, P.O. Box 90153, 5000 LE Tilburg, the Netherlands \\ ${ }^{5}$ University of Twente, Faculty of Geo-Information Science and Earth Observation, P.O. Box 217, 7500 AE Enschede, the Netherlands
}

To feed this and the next generations, sustainable development is considered the only viable future for agriculture. The successful implementation of sustainable development has remained an elusive goal in agriculture. Innovation initiatives in agriculture, such as TransForum in the Netherlands, have tried to provide best practice to start such innovations in agrifood chains and networks. In its 6 year existence, between 2004 and 2010, Transforum has been an intermediary between knowledge institutes, entrepreneurs, NGO's and governmental organisations. This has resulted in several successful innovation initiatives in Dutch agriculture and a wealth of knowledge on organising networks and chains for sustainable innovation. TransForum has operated from its vision that metropolitan agriculture is the way forward for sustainable development in the Dutch agriculture sector and posited 4 central elements of successful innovation: (1) shared image creation; (2) relevant inventions for sustainability; (3) dealing with institutional context; and (4) the creation of market directed chains for sustainable products (Fischer et al., 2012; Veldkamp et al., 2009).

The current special issue includes six papers from TransForum and an seventh paper outlining an international perspective on corporate social responsibility.

The development of shared images is shown to relate to existing frames of mind by Zwartkruis, Moors, Farla and van Lente (2012). They show that framing specific properties of an innovation can considerably affect its acceptance and success. In their case study Zwartkruis and colleagues discuss the framing of the Roundel laying hen system. Originally it was perceived as a 'circus tent' standing out in the landscape. After a while it was successfully reframed as a 'hill' that fitted in the environment and thus matched with the image of sustainability. This was further emphasised by chickens walking outside and plants surrounding the henhouse. In addition, the institutional problems that arose when the Roundel system was imagined as a new concept were solved by framing the Roundel as a combination of (variations of) existing concepts. This example demonstrates that specific framing of an innovative concept plays an essential role in achieving institutional acceptance of the innovation. Hoes, Regeer and Zweekhorst, (2012) illustrate similar issues when discussing agro-parks, where the ideas for a very innovative Delta park, although considered unacceptable by several stakeholders, were later used as a golden standard for future initiatives. In this case, more modest and more realistic initiatives were considered lacking to this standard. Delta park had created an image that inspired some actors to innovate and triggered other actors to oppose, but it had also created an unrealistically high level of ambition. To aim for these high ambitions, the development of agro-parks was a capital intensive, high risk investment, making financing of the innovation a major issue.

Taanman, Wittmayer and Diepenmaat (2012) monitored the vision development in the TransForum program itself. They show that the development of TransForum follows current views on the development of corporate social responsibility as the innovation programme developed from a traditional subsidising platform, to a more active and coordinating program which directed programme innovations based on an integrative vision. Taanman distinguishes four phases in this development of the programme starting from an initial open view on developments and monitoring projects, to the development of the actual vision where considerable effort had to be invested in aligning the programme vision with those of the projects it sponsored and with societal visions in general. This resulted in a third phase where the emphasis shifted from a programme of individual projects, to a programme managing a portfolio of projects, which together could provide an impetus to sectorial changes. The fourth phase was the anchoring of the results to go beyond the life span of the TransForum program. Taanman and colleagues emphasise that the major changes that went on inside the TransForum program itself should not be neglected as these are essential to understand the position of portfolios managed by intermediaries like TransForum.

De Goede, Gremmen and Blom-Zandstra (2012) provide a suggestion how to actually develop a sustainable production 
chain. They notice that the current agricultural sector is mainly optimising towards cost reduction for commodities. The people-planet-profit triple bottom line optimisation is a multidimensional challenge, in which the dimensions are not only related (often negatively), but also there is no necessary agreement on the weight of the dimensions. This makes multidimensional optimisation practically impossible, the more so since minor disturbances in one of the bottom lines may result in unacceptable effects on the other(s). This may play out in the societal debate, where agro parks are measured against golden standards (Hoes et al., 2012), or may threaten innovations where specific natural frames cannot be adapted to a realistic sustainability aim (Zwartkruis et al., 2012). In the market place such difficulties are often circumvented by not specifying a strict definition of sustainability. Verhees et al. (2012), for example, define sustainability as a desire of society towards production standards, while Meijers and Van Dam (2012) define sustainable development in food production as the development of food that is 'less likely to come at the expense of people, animals and the planet'. These definitions hold a vision, but tend to be rather vague in their implementation, which challenges food companies to understand and integrate sustainability in their business practices and strategies (Poetz et al., 2012). Where the other papers recognise a problem in managing sustainability and circumvent it, de Goede et al. (2012) analyse robustness against disturbances for the development of sustainable systems. A robust system provides guarantees against risks, as the system itself is capable to withstand or recover from sub-optimal developments in its environment. De Goede et al. (2012) observe that robustness in creating sustainable agriculture follows a longstanding focus in technology on efficiency through control, which resulted in complex multiple redundant systems as applied in aeroplanes and nuclear power plants. Limitations of this approach are however that unanticipated external effects may easily push such controlled systems beyond controllable limits. De Goede et al. (2012) argue that sustainability may better be served by considering other ways of specifying robustness, for example by investigating systems that can perform in, or adapt to, a range of changing circumstances.

Poetz, Haas and Balzarova (2012) delve into institutionalisation of corporate social responsibility initiatives, by studying effort of some major multinational food companies in creating joint programmes. They recognise that both in entrepreneurial and market orientations of these firms, responsible entrepreneurial behaviour has become part of best practice in doing business. Multinational companies have the financial means to create ambitious integrative projects and to enforce chain integration towards sustainability; and have thus more power than small firms (e.g. those willing to cooperate in agroparks as outlined in Hoes et al., 2012). Institutional difficulties do however arise for global implementation of sustainability, which involve anti-trust laws and different legal frames for defining sustainability. Where a lot of these papers study institutional barriers and orientation of innovators on other companies and entrepreneurs in the section, Verhees, Lans and Verstegen (2012) compare entrepreneurs aiming at sustainable development from an entrepreneurial orientation, with those approaching development from a market orientation. In their paper they show that both a market orientation and an entrepreneurial orientation may result in successful innovation in sustainable agriculture, however, depending on the orientation adopted, the emphasis of the innovation will be different. Where innovations in both orientations aim at cost reduction, entrepreneurial orientation leads to an emphasis on upscaling of operations, compared to firms with a stronger market orientation. Entrepreneurial orientation leads to a strategy of starting up new initiatives, while market orientation results in more collaboration with buyers in the chains and networks as part of the strategy of the company. Verhees and colleagues do not notice differences in success between both orientation types. However, in our view the differences lie in the incentive for the innovations that is gained from increased operational efficiency in the entrepreneurial orientation and in added value generated by more consumer purchase in the market orientation (Van Trijp and Fischer, 2011). For the latter sustainable markets need to be understood. Meijers and van Dam (2012) investigate the sustainable market. To do so, they bring together over 25 years of literature on the marketing of environmental and sustainable products; which shows a broad range of predictions who will buy sustainable products for what reason. In an effort to test these, Meijers and van Dam (2012) analyse actual purchase data of sustainable products, in combination with self-reported data on values and attribute appreciation. Their results show the complexity of consumer behaviour towards sustainable purchase, where the youngest and oldest consumers buy most sustainable products. Concerns about specific product attributes determine whether specific consumers buy these products. Additionally, for consumers who buy these products, concerns about the attributes also determine how many of those products consumer buy. General value patterns determine how many sustainable products are chosen, but do not distinguish between consumers who buy no, or some sustainable products. In a final note Meijers and van Dam (2012) notice that most sustainable products sold in the Netherlands are those of major national brands that decided to adopt a sustainability program. Although 
the packages show certified sustainability logos Meijers and van Dam (2012) argue that it is more likely that the perceived quality associated with the brand, rather than the sustainability attribute is the dominant reason for purchase. This would argue for the entrepreneurial collaboration among major (inter)national brands following the paper by Poetz et al. (2012).

By bringing these seven papers together in this special issue, we show the relevance to manage images of sustainability, to choose the relevant optimisation target for technological development, to monitor intermediaries and other institutions and the barriers they may create and the importance of involving a clear entrepreneurial or market perspective when engaging in sustainable development.

\section{References}

De Goede, D., B. Gremmen and M. Blom-Zandstra, 2012. Robustness as an image of sustainability: applied conceptualisations and their contribution to sustainable development. Journal of Chain and Network Science, 12(2): 137-149.

Fischer, A.R.H., P.J. Beers, H. van Latesteijn, K. Andeweg, E. Jacobsen, H. Mommaas, H.C.M. van Trijp and A. Veldkamp, 2012. Transforum system innovation towards sustainable food. A review. Agronomy for Sustainable Development, 32(2): 595-608.

Hoes, A.-C., B.J. Regeer and M.B.M. Zweekhorst, 2012. Innovation projects and visions on the future: ambition and commitment in the Agropark case. Journal on Chain and Network Science, 12(2): 111-124.

Meijers, M.H.C. and Y.K. van Dam, 2012. Sustainable food purchases in the Netherlands: The influence of consumer characteristics. Journal on Chain and Network Science, 12(2): 181.198.

Poetz, K., R. Haas and M. Balzarova, 2012. Sustainability and food corporations? Emerging strategic CSR partnership initiatives in agribusiness: The case of the Sustainable Agriculture Initiative (SAI) Journal on Chain and Network Science, 12(2): 151-165.

Taanman, M., J.M. Wittmayer and H. Diepenmaat, 2012. Monitoring on-going vision development in system change programmes. Journal on Chain and Network Science, 12(2): 125-136.

Van Trijp, H.C.M. and A.R.H. Fischer, 2011. Mobilizing consumer demand for sustainable development. In: van Latesteijn, H.C. and K. Andeweg (eds.), Transforming agro innovation toward sustainable development: the TransForum model, Springer, Dordrecht, the Netherlands, pp. 79-103.

Veldkamp, A., A.C. Van Altvorst, R. Eweg, E. Jacobsen, A. Van Kleef, H. Van Latesteijn, S. Mager, H. Mommaas, P.J.A.M. Smeets, L. Spaans and J.C.M. Van Trijp, 2009. Triggering transitions towards sustainable development of the Dutch agricultural sector: TransForum's approach. Agronomy for Sustainable Development, 29(1): 87-96.
Verhees, F.J.H.M., T. Lans and J.A.A.M. Verstegen, 2012. The influence of market- and entrepreneurial orientation on strategic marketing choices: the cases of Dutch farmers and horticultural growers. Journal on Chain and Network Science, 12(2): 167-180.

Zwartkruis, J.V., E.H.M. Moors, J.C.M. Farla and H. van Lente, 2012. Agri-food in search of sustainability: cognitive, interactional and material framing. Journal on Chain and Network Science, 12(2): 99-110. 
